\title{
Neural networks for optimal operation of a run-of-river adjustable speed hydro power plant with axial-flow propeller turbine
}

\author{
Juan I. Pérez-Díaz and Jesús Fraile-Ardanuy, Member, IEEE
}

\begin{abstract}
This paper analyzes the regulating capabilities of both turbine speed and guide vanes position in an axial-flow propeller turbine. Two neural networks are implemented in order to simulate the turbine behavior and the turbine efficiency. A maximum-efficiency-tracking algorithm is developed to set the guide vanes position.

An experimental power plant built in the Hydraulics Laboratory is described. In order to validate the proposed operation control, the dynamics of this run-of- river pilot plant has been simulated. Substantial increases in the turbine efficiency have been found.
\end{abstract}

\section{INTRODUCTION}

$\mathrm{H}$ YDROPOPWER is considered to be the most cost effective renewable energy source, currently providing over $80 \%$ of all renewable energy. Although it is a competitive and mature technology, with more than a century of experience, there still exists a large technically feasible hydropower potential to be developed, widely spread all over the world [1].

Small Hydro Power (SHP), understood as the energy generated in any hydro power plant rated at $10 \mathrm{MW}$ or less, has a huge and yet untapped potential specially in low head systems and in the so-called run-of-river hydro plants [2], usually associated to a small reservoir or head pond, if any, where the water intake is located. In 2005, total SHP capacity in operation in Europe was 11601 MW. 54\% of European capacity is located in three countries: Italy is leader (2405.5 MW), followed by France (2060 MW) and Spain (1788 MW) [3].

In run-of-river hydro plants generated power must be continuously adapted to the actual river inflow. This requires monitoring of the water level at the intake and adjusting the flow through the turbine so as to maintain the level within pre-specified limits. Very few references on water level control in hydropower plants have been found in technical literature [4-6].

If conventional hydro generating units are used, head and discharge deviations from the design point involve important decreases in efficiency. By using variable speed hydro generating units, it is possible to avoid this drawback since variable speed operation (VSO) allows the turbine speed to change in accordance with hydraulic conditions so

J. I. Pérez is with the Technical University of Madrid, Spain (phone: (+34)-91-3366706; e-mail: jiperez@caminos.upm.es)

J. Fraile-Ardanuy is with the Polythecnic University of Madrid, Spain. (phone: (+34)-91-3365354; e-mail: jefar@ caminos.upm.es). that the efficiency can be improved. In these cases, if the turbine has adjustable guide vanes, two variables are available for turbine control, turbine speed and guide vanes position. One of them can be used to keep the water level within limits whereas the other one can be used to adapt the turbine conditions to actual values of head and discharge.

Usually, water level is kept constant by changing the guide vanes opening [7-9], but in some cases, the regulating capability provided by the turbine speed can be greater than that provided by the guide vanes position. Such is the case of the axial-flow propeller turbine studied in this paper. Therefore, turbine speed has been selected as control variable, to maintain a constant water level in the head pond, as in the study presented in [10].

Axial-flow propeller turbines are high-order, uncertain and non-linear systems and it is really difficult to obtain their mathematical model. Therefore, it is usual to represent the turbine behaviour by numerical tables or hill curves, but if an advanced control strategy is going to be developed, an accurate model is needed in order to perform nonlinear simulations [11].

This paper presents a neural model of an axial-flow propeller turbine of a run-of-river adjustable speed hydro pilot power plant. An ANN has been trained to reproduce the performance of this turbine, using training data obtained from the field measurements gathered on a test bench.

Besides, a maximum-efficiency-tracking algorithm has been developed to set the optimal guide vanes position. Main characteristics of the pilot plant are described in detail and numerical simulations are presented and further discussed.

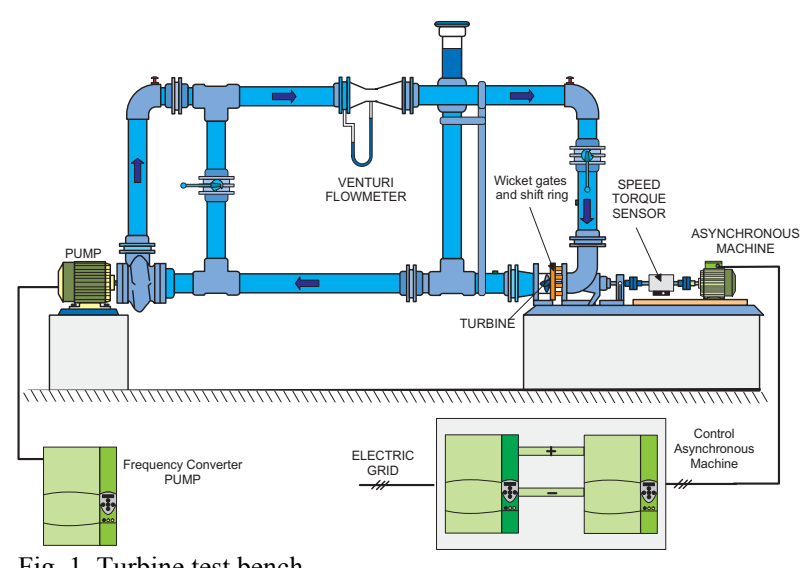

Fig. 1. Turbine test bench. 